\title{
A NAÇÃO IRREALIZÁVEL DE CORNÉLIO PENNA
}

Josalba Fabiana dos Santos*

RESUMO:

Os romances de Cornélio Penna podem ser lidos como metáforas e metonímias de uma nação impossivel de ser constituir porque será eternamente assombrada pela escravidão.

PALAVRAS-CHAVE: mistério, nação, escravidão, Cornélio Penna.

Cornélio de Oliveira Penna nasceu em Petrópolis em 1896 e faleceu na cidade do Rio de Janeiro em 1958, onde viveu a maior parte da vida. Depois de abdicar da carreira de pintor, dedicou-se à literatura, publicando quatro romances: Fronteira (1935), Dois romances de Nico Horta (1939), Repouso (1948) e A menina morta (1954), o mais conhecido. Escritor católico e com fortes traços intimistas, teve sua obra relegada a segundo plano no cânone literário nacional. Isso se deve, em parte, ao enorme sucesso que fizeram os autores do Nordeste que se lançaram mais ou menos na mesma época, tanto junto ao público quanto à crítica.

0 clima de mistério que perpassa os livros de Cornélio Penna é intrigante. Principalmente porque não existe uma tradição do gênero na literatura brasileira. 0 que intensifica a curiosidade do leitor é o fato de não se tratar de romance gótico - como o quer Luiz Costa Lima (1976: 56). É verdade que algumas das características marcantes desse desdobramento do Romantismo são encontradas com facilidade: atmosferas penumbrosas e soturnas, tempo recuado, ambientes isolados, fantasmas, protagonistas como casos psicológicos. Há também um aspecto moral que dá o sentido do gênero: o Ma1 como o limite extremo e devastador que pode alcançar o humano (Moisés, 1985: 263-264). Porém, esses elementos por si só não são suficientes para uma classificação rígida. No romance gótico eles têm uma função: dar sustos, deixar o leitor com medo.

* Doutora em Letras: Literatura, História e Memória Cultural (Área de concentração: Literatura Comparada), 2004. 


\section{EMTESE}

Belo Horizonte, v. 9, p. I-28I, dez. 2005

Na narrativa corneliana, o mistério encobre com a mesma intensidade que revela e nesse jogo expõe os mecanismos de construção da história do país.

Durante vários anos, a fortuna crítica dessa obra limitou-se a uma leitura apressada, que resultou basicamente em artigos publicados em periódicos e algumas menções nas histórias literárias. No Boletim de Ariel (1936), no calor de uma primeira recepção, o escritor Octávio de Faria vê "dons de indagação introspectiva" em Cornélio Penna. Duas décadas mais tarde, 01 ívio Montenegro menciona o mistério e o lado psicológico (1953: 239). Adonias Filho, um dos primeiros a se entusiasmar com o romancista, tece alguns comentários que valorizam seu talento para fundir a "temática nativista e documentária" a um "roteiro existencial" (1960: 9). As narrativas não se limitam a tratar de dramas intimistas; a subjetividade está inserida num contexto social e político dinâmico que repercutirá nesses dramas.

Alfredo Bosi, na História concisa da literatura brasileira, como grande parte de críticos contemporâneos às primeiras publicações dos livros cornelianos, salientará o aspecto psicológico e o mistério, mas para tomar rumo diverso do de seus antecessores. Criticando Mário de Andrade, que via a Viajante, personagem de Fronteira, e assombrações como excessos despropositados, Bosi tenta justificá-los: "se o romance de Cornélio Penna desenrola-se no ritmo do sonho, então há lugar para seres que não tenham outra corporeidade além da própria e fugidia imagem" (1987: 471). Os fantasmas comparecem como necessários à estrutura romanesca proposta pelo escritor e como resultado de um universo opressor.

Afrânio Coutinho (1986: 408), por sua vez, descreve a obra corneliana como "reação ao romance do Nordeste" e, além de aproximá-1a de Dostoiévski, também a relaciona com Camilo Castelo Branco, Machado de Assis e Raul Pompéia. Estes dois últimos articulariam um paradigma "interiorista" dentro da literatura brasileira do qual Cornélio seria um sucessor. Quanto a seus livros se apresentarem como "reação ao romance do Nordeste", parece uma posição apressada e inconsistente. 0 escritor fluminense esteve distante de polêmicas durante toda a sua vida e nunca se declarou contrário à denúncia ou à estética proposta pelos ficcionistas nordestinos, apenas escolheu outros caminhos para tratar o "mundo real". Um estudo que aproximasse $S$. Bernardo, de Graciliano Ramos, de A menina morta, por exemplo, soaria como bastante possível à luz da exploração do homem pelo homem e da ruína. 
Antonio Candido e José Aderaldo Castel1o (1977: 320) não tomarão caminhos diferentes dos expostos: mistério e psicológico serão seus rótulos. Acrescentando, como outros o fizeram, que Cornélio Penna era católico. Fato que, regra geral, tende a ser colocado de forma depreciativa, quando se confunde catolicismo com carolismo (Bueno, 1996). Segundo Antonio Candido (1989: 185), há uma "polarização ideológica" nos anos 1930: de um 1ado, os escritores ligados a questões sociais e automaticamente associados a um pensamento de esquerda e, de outro, os católicos, associados à direita. Os críticos igualmente corresponderiam a essa divisão, não apenas no território político, o que seria natural, mas no intelectual, o que gerava discriminação e apagamento dos escritores que se alinhassem na oposição.

A perversão do trapezista (1976), de Luiz Costa Lima, foi o primeiro trabalho de longo fôlego sobre a obra de Cornélio Penna. Passados quase trinta anos da publicação, ainda é o único livro dedicado integralmente a ela, o que confirma os freqüentes comentários a respeito de uma fortuna crítica escassa. De inspiração estruturalista, A perversão do trapezista empreende uma trajetória que toma $A$ menina morta como referente bem acabado e agrega os demais romances como variantes mais ou menos débeis. Fronteira, Dois romances de Nico Horta e Repouso trariam em germe vários dos elementos que aflorariam na plenitude no último romance. Alguns desses elementos seriam a sexualidade reprimida, a morte, o duplo e o clima de mistério.

Em artigo intitulado "As linguagens do modernismo" (1975), o crítico já havia dedicado uma rápida análise à obra corneliana. Mas será em "Sob as trevas da melancolia: o patriarcado em A menina morta" (1989) que fará uma aproximação com Casa-grande \& senzala (1933), de Gilberto Freyre. Comparando a visão solar do ensaísta ao retratar o patriarcado e a escravidão com o aspecto sombrio desse mesmo sistema em Cornélio Penna, Costa Lima propõe uma leitura até então inexplorada. A idéia não é original, Maria Aparecida Santilli (1974) a havia proposto anteriormente. Todavia, é o crítico quem dedicará um artigo específico, em $A$ aguarrás do tempo (1989), sobre o assunto, tanto para A menina morta quanto para Casa-grande \& senzala.

A configuração patriarcal-escravocrata não se limita a contextualizar a narrativa corneliana nem tampouco se restringe ao último romance, o único que se ambientaria antes da Abolição. Nos três primeiros livros, apesar de se referirem ao 


\section{EMTESE}

Belo Horizonte, v. 9, p. I-28I, dez. 2005

Brasil posterior à queda do Império, existem fortes traços da presença recente do regime escravocrata na pele negra dos criados e nas alusões à condição de cativos de alguns num passado próximo. 0 patriarcalismo igualmente se mantém vivo na memória dos membros de famílias social e economicamente decaídas. Em A menina morta, o pater familias não é apenas uma lembrança, mas um dos personagens, e a escravidão faz parte do dia-a-dia da fazenda cafeicultora. Abre-se uma lacuna, rompe-se com o continuum da história como propõe Walter Benjamin (1993). O romance apresenta uma espécie de narrativa de fundação nacional, porém invertida. Existe um temor constante de uma revolta dos negros, que impossibilita a construção de um mito original. 0 sentido é diverso do de Casa-grande \& senzala porque em Freyre o relacionamento é harmônico desde o título; há um idîlio entre o branco e o negro. Porém, se a escravidão é proposta de forma diversa, a família se constitui de forma semelhante.

É comum estabelecer ligações entre a formação do Estado nacional moderno e um certo nível intelectual, científico e tecnológico (cf. Elias, 1993). Mas não há formação em Cornélio Penna e muitos dos problemas advêm da superposição entre civilização e barbárie. Cunhou-se um discurso em torno da idéia de que a nação só é possível se houver progresso, ao mesmo tempo em que se apaga o que não couber nesse projeto. Há um abismo aparentemente intransponível, mas após percorrer imbricados caminhos se percebe que a civilização advém da barbárie. Afinal, é o negro, rebaixado intelectualmente em diversas passagens, que dá suporte ao desenvolvimento nacional. Por ironia, a divisa da família de $A$ menina morta é Spes et labor (Penna, 1997: 116). Se - futuro pode ser aguardado com algum entusiasmo é às custas do trabalho escravo: portanto está comprometido.

Raymundo Faoro, em Os donos do poder (2001), discute o encolhimento do público pelo privado, fazendo um levantamento histórico que se inicia em Portugal até chegar ao Brasil. Por sua vez, Roberto Schwarz (1988; 1990; 1997) trata o favor nas relações econômicas e sociais no século XIX a partir dos romances de Machado de Assis. Como o trabalho assalariado era escasso em função da escravidão, as pessoas brancas ou libertas pobres se viam na condição de viver do favor dos ricos e poderosos. Estabelecia-se um regime de troca que tornava a exploração ainda 
mais truculenta. É o que ocorre na obra corneliana, pois denuncia o sistema além da escravidão. Os parentes pobres ou agregados à casa-grande devem prestar toda a sorte de serviço ao patriarca, que em troca os protege protege-os do despotismo de um outro patriarca qualquer. Apesar de os romances estarem aparentemente circunscritos ao universo doméstico, deve-se pensá-1os como simbólicos: a família seria metáfora e metonímia da nação.

0 Mal está à espreita nos livros de Cornélio Penna e repercute na atmosfera de mistério. Aquele que erra, que se desvia da lei merece ser punido. Nesse caso, existiriam concomitantes duas grandes normas: a dos homens e a de Deus. Obedecendo-se a lei humana, pode-se estar infringindo a divina. A discussão que Mikhail Bakhtin (1988) faz sobre o cronotopo a partir de 0 asno de ouro, de Apuleio, revela a idéia do crime como o ato que dá dimensão pública ao privado; o crime divulga a vida íntima. Todos são dignos de castigo em Cornélio, pois expiam o pecado original. E todos são mais ou menos responsáveis por crimes mais ou menos metafóricos. Atos que se desviam do "caminho correto" expõem publicamente a privacidade dos envolvidos, porém há um esforço no sentido de evitar essa exposição. 0 esforço não elimina a publicidade, mas confunde o público espectador - e o leitor -, contribuindo para gerar mistério. Como todos são pecadores e quase todos criminosos, o paraíso está perdido, especialmente para os poderosos, principais agentes da exploração.

No Posfácio (1997) de A menina morta, Wander Melo Miranda propõe a escravidão como o grande fantasma nacional que compromete o presente e o futuro como possibilidades de transformação, tal como expressa a obra de Cornélio Penna:

A cronologia histórica inverte [...] a cronologia de publicação dos romances, direcionando o romancista para o resgate da herança do passado, onde se localizaria o processo de formação da nossa nacionalidade, que o período escravocrata traduz sob a forma de um violento dissenso. Ao colocá-10 em cena como nenhum outro romancista entre nós, Cornélio Penna não só estaria problematizando a pretensa unidade que nos constituiria enquanto nação, mas assinalando a permanência de um conflito não sanado na origem e que, sob a forma de um fantasma desagregador, continua a nos assombrar e a nos manter exilados no passado, como num pesadelo que parece não ter fim. (Miranda, 1997: 482)

0 fantasma não se limita a assombrar, também deforma a nação, portanto faz dela um monstro. É daí que provém o mistério da narrativa corneliana: não há almas penadas e sim histórias mal contadas. Como o que se teme no outro é o reflexo 


\section{EMTESE}

Belo Horizonte, v. 9, p. I-28I, dez. 2005

do que se traz em si mesmo, a identidade é distorcida a tal ponto que a imagem torna-se irreconhecível, contribuindo para o travamento da configuração nacional.

Em A menina morta: a insuportâvel comédia (1979), Wander Melo Miranda desenvolve uma relação entre o espaço na narrativa e o teatro. A relação é proposta pelo próprio romance na medida em que utiliza constantemente várias metáforas do campo cênico como palco, bastidores e representação. Além da análise desse processo como um todo, também há um estudo mais específico sobre a máscara e o espelho. A partir disso, pode-se pensar numa aproximação entre a escravidão como fantasma e a necessidade da representação teatral como recurso dissimulador das cicatrizes (na pele de uns e na memória de outros). A narrativa ficcional se valeria desse estratagema para revelar o complexo processo histórico. Os espelhos funcionariam como metáforas e metonímias narrativas que mostram e escondem os acontecimentos e seus personagens - são parte da história ao mesmo tempo em que são como se fossem a miniatura da história maior.

Todo teatro, para se fazer espetáculo, necessita de público. Nos romances abordados, "atores" e "espectadores" se confundem porque os que atuam são os que assistem. Essa troca de papéis não é apenas recurso cênico, mas elemento auxiliar de exposição temática. 0 que se mostra, o "espetáculo", é manipulado pelos interesses privados do patriarca. No entanto, esses interesses não correspondem a uma única individualidade. Eles são importantes para um grupo social relativamente grande, mas que está muito longe de atender a vontade de todos. Tal grupo se valerá da maioria para ser satisfeito nos seus próprios interesses: o público é posto a serviço do privado e a representação teatral em Cornélio Penna, somada a outros elementos, expõe essa situação.

0 mito do Brasil edênico configurou o nacional deformado desde o período anterior à "descoberta". Com o passar dos séculos, foi pouco a pouco sendo substituído pelo do progresso. Quando Cornélio Penna publica seu último romance (1954), o país passa por uma fase de grande apelo modernizador. Visto ser um escritor preocupado em retratar o passado, é natural que seja arredio a transformações abruptas: "0 mundo apodreceu, envenenou-se de civilização" (Penna, 1958: xlvi). 0 resultado é uma obra que trava qualquer possibilidade de fundação nacional. Sem esperança de 
redenção no futuro, só restaria o recurso de retorno à memória. Mas, ao tornar visiveis as lacunas da história, o escritor deixa escapar apenas fantasmas e monstros, evidenciando a ausência de saídas que a sua narrativa labiríntica propõe.

ABSTRACT :

Cornélio Penna's novels can be read as metaphors and metonymies for an unfeasible nation, eternally haunted by slavery.

KEY WORDS: mystery, nation, slavery, Cornélio Penna.

\section{REFERÊNCIAS BIBLIOGRÁFICAS}

AdONiAS Filho. Cornélio Pena. Rio de Janeiro: Agir, 1960.

BAKHTIN, Mikhail. Formas de tempo e de cronotopo no romance. In: BAKHTIN, Mikhail. Questões de literatura e de estética. São Paulo: Ed. Unesp; Hucitec, 1988. p. 211-362.

BENJAMIN, Walter. Magia e técnica, arte e politica: Ensaios sobre literatura e história da cultura. Trad. Sergio Paulo Rouanet. 6. ed. São Paulo: Brasiliense, 1993. v. 1.

BOSI, Alfredo. Cornélio Pena. História concisa da literatura brasileira. São Paulo: Cultrix, 1987. p. 469-472.

BUENO, Luís. A intensidade do pecado. Folha de S. Paulo, São Paulo, 29 dez. 1996.

CANDido, Antonio; CASTELlo, José Aderaldo. Presença da literatura brasileira. 6. ed. Rio de Janeiro; São Paulo: Difel, 1977. v. 3.

CANDIDO, Antonio. Literatura e subdesenvolvimento. In: CANDIDO, Antonio. A educação pela noite e outros ensaios. 2. ed. São Paulo: Ática, 1989. p. 140-162.

COUTINHO, Afrânio. A literatura no Brasil. 3. ed. Rio de Janeiro: José 0lympio; Universidade Federal Fluminense, 1986. v. 5.

ELIAS, Norbert. O processo civilizador: Formação do Estado e civilização. Trad. Ruy Jungmann. Rio de Janeiro: Jorge Zahar, 1993. v. 2.

FAORO, Raymundo. Os donos do poder: Formação do patronato politico brasileiro. 3. ed. São Paulo: Globo, 2001.

FARIA, Octávio de. Fronteira. Boletim de Ariel, Rio de Janeiro, 12 set. 1936.

FREYRE, Gilberto. Casa-grande \& senzala. 41. ed. Rio de Janeiro: Record, 2000. 


\section{EM TESE}

Belo Horizonte, v. 9, p. I-28I, dez. 2005

LIMA, Luiz Costa. Ficção: As 1inguagens do modernismo. In: ÁVILA, Affonso. O modernismo. São Paulo: Perspectiva, 1975. p. 69-86.

LIMA, Luiz Costa. A perversão do trapezista: 0 romance em Cornélio Penna. Rio de Janeiro: Imago, 1976.

LIMA, Luiz Costa. Sob as trevas da melancolia: o patriarcado em A menina morta. In: LIMA, Luiz Costa. A aguarrás do tempo. Rio de Janeiro: Rocco, 1989. p. 239284.

MIRANDA, Wander Melo. A menina morta: a insuportável comédia. Dissertação (Mestrado em Literatura Brasileira) - Universidade Federal de Minas Gerais, Belo Horizonte, 1979.

MIRANDA, Wander Melo. Posfácio. In: PEnNA, Cornélio. A menina morta. Rio de Janeiro: Artium, 1997. p. 472-482.

MOISÉS, Massaud. Dicionário de termos literârios. 4. ed. São Paulo: Cultrix, 1985.

MONTENEgRo, 01 ívio. Cornélio Pena. In: MONTENEgRo, 01 ivio. O romance brasileiro. 2. ed. Rio de Janeiro: José 01 ympio, 1953.

PENNA, Cornélio. Romances completos. Rio de Janeiro: Aguilar, 1958.

PENNA, Cornélio. A menina morta. Rio de Janeiro: Artium, 1997.

PENNA, Cornélio. Repouso. Rio de Janeiro: Artium, 1998. PENNA, Cornélio. Fronteira. Rio de Janeiro: Ediouro, [s.d.].

SANTILLI, Maria Aparecida. A menina morta. Kindlers Literatur Lexicon. Munique: Deutscher Taschenbuch Verlag, 1974. v. 14.

SCHWARZ, Roberto. Ao vencedor as batatas. São Paulo: Duas Cidades, 1988.

SCHWARZ, Roberto. Um mestre na periferia do capitalismo: Machado de Assis. São Paulo: Duas Cidades, 1990.

SCHWARZ, Roberto. Duas meninas. São Paulo: Companhia das Letras, 1997. 